\title{
Effectiveness of Endobronchial Coil Treatment for Lung Volume Reduction in Patients with Severe Heterogeneous Emphysema and Bilateral Incomplete Fissures: A Six-Month Follow-Up
}

\author{
Konstantina Kontogianni ${ }^{\mathrm{a}}$ Vasiliki Gerovasili ${ }^{\mathrm{a}}$ Daniela Gompelmann ${ }^{\mathrm{a}}$ \\ Maren Schuhmann ${ }^{a} \quad$ Claus Peter Heussel $^{b}$ Felix J.F. Herth ${ }^{a}$ Ralf Eberhardt ${ }^{a}$ \\ Departments of a Pulmonology and Respiratory Care Medicine and ${ }^{\mathrm{b}}$ Diagnostic and Interventional Radiology, \\ Thoraxklinik at the University of Heidelberg, Heidelberg, Germany
}

\section{Key Words}

Chronic obstructive pulmonary disease $\cdot$ Emphysema .

Endoscopic lung volume reduction · Endobronchial coils

\begin{abstract}
Background: Treatment with lung volume reduction coils (LVRC) may be effective in patients with severe heterogeneous emphysema and incomplete fissures. Objective: We hypothesized that LVRC placement improves pulmonary function, exercise tolerance and quality of life in these patients. Methods: Twenty-six patients with chronic obstructive pulmonary disease (COPD), 13 males and 13 females, aged $66 \pm 8$ years with heterogeneous emphysema and incomplete fissures were included in this retrospective analysis. The coils were implanted unilaterally in the upper or lower lobe. Patients were followed up at 30,90 and 180 days after treatment and changes in pulmonary function test and 6-minute-walk-test (6MWT) values as well as scores for the modified Medical Research Council (mMRC) dyspnea scale and the St. George's Respiratory Questionnaire (SGRQ) were recorded. Results: $\mathrm{FEV}_{1}$ improved significantly at 90 days and tended to decrease at the 180-day follow-up $(0.67 \pm 0.17$ vs. $0.78 \pm 0.25$ vs. $0.73 \pm 0.21$ liters, respectively, $p<0.001$ ) The 6MWT score had improved significantly at 90 days and had tended to decrease at the 180-day follow-up (216 \pm 107
\end{abstract}

vs. $262 \pm 97$ vs. $262 \pm 112 \mathrm{~m}$, respectively, $\mathrm{p}=0.001)$. SGRQ was significantly improved at 90 days. Multivariate analysis showed that worse 6MWT performance at baseline was independently associated with a greater improvement in $6 \mathrm{MWT}$ at the 90-day follow-up. The total complication rate was $54 \%(n=14)$ and included light hemorrhage in 6 patients, COPD exacerbation in 6, pneumothorax in 1 and both COPD exacerbation and pneumothorax in 1 patient. Conclusions: This is the first study to show that LVRC in patients with heterogeneous emphysema and incomplete fissures improves exercise capacity, quality of life and lung function up to 90 days after the intervention. Further studies are needed to assess the long-term effects of LVRC in these patients.

(C) 2014 S. Karger AG, Basel

\section{Introduction}

Epidemiological estimates predict an increase in patients with chronic lung diseases such as COPD [1]. Therapeutic options for patients with COPD and severe em-

V. Gerovasili and K. Kontogianni contributed equally to this manuscript.

\section{KARGER}

E-Mail karger@karger.com

www.karger.com/res
(C) 2014 S. Karger AG, Basel

0025-7931/14/0881-0052\$39.50/0
Ralf Eberhardt, MD

Pneumology and Respiratory Care Medicine

Thoraxklinik at the University of Heidelberg

Amalienstrasse 5, DE-69126 Heidelberg (Germany)

E-Mail ralf.eberhardt@med.uni-heidelberg.de 
physema with gas trapping and hyperinflation are limited. Lung volume reduction surgery has been applied as a palliative treatment in selected patients but even though the concept is excellent, the referral of patients has been severely influenced by significant perioperative morbidity as well as mortality [2-4].

Less-invasive techniques have since been developed, with endoscopic lung volume reduction (ELVR) by means of endobronchial valve placement being the most widespread so far [5-11]. The frequent presence of incomplete fissures as a parameter for collateral flow [1214], a limiting factor in ELVR with valves, indicates the need for ELVR treatments that work independently of collateral ventilation [12]. Treatment with lung volume reduction coils (LVRC) overcomes this limiting factor and might serve as an alternative choice in this specific group of patients.

We hypothesized that ELVR using coils can improve pulmonary function, exercise tolerance and quality of life (QoL) in patients with severe heterogeneous emphysema and incomplete fissures. The primary end point in our study was the improvement in $\mathrm{FEV}_{1}$ at 180 days. Secondary end points included the improvement in pulmonary function test (PFT) and 6-minute-walktest (6MWT) values and QoL at 180 days. Secondary end points also included identification of preprocedural clinical, radiological or endoscopic characteristics which could correlate with good postprocedural outcome.

\section{Materials and Methods}

This was a single-center, retrospective analysis of a patient cohort. Patients with severe heterogeneous emphysema and incomplete interlobar fissures were included after providing written consent. The study protocol was approved by the ethics committee of the University of Heidelberg.

Patients had initially been considered for ELVR valve placement, but were excluded due to the presence of bilaterally incomplete interlobar fissures on thin-section multislice computed tomography (MSCT) [12]. Our radiologists visually assessed each patient's baseline MSCT, and each fissure with a defect of $>10 \%$ was considered as incomplete [15]. Chartis analysis was not performed. All patients were treated by means of ELVR with the placement of LVRC. ELVR treatment is part of the standard clinical care of patients with severe COPD in our hospital. Inclusion criteria were: predominantly unilateral heterogeneous emphysema and bilaterally incomplete fissures as well as previously documented criteria for $\mathrm{ELVR}$, i.e. $\mathrm{FEV}_{1}<40 \%$, residual volume (RV) $>200 \%$ predicted and total lung capacity (TLC) $>100 \%$ predicted (table 1 ) $[5$, $7,8]$.

The heterogeneity of the emphysema was visually determined by nonenhanced thin-section CT scan. Images were processed
Table 1. Main inclusion and exclusion criteria

\author{
Main inclusion criteria \\ $\mathrm{FEV}_{1}<40 \%$ of predicted \\ TLC $>100 \%$ of predicted \\ RV $>200 \%$ of predicted \\ Heterogeneous emphysema \\ Incomplete interlobar fissures bilaterally \\ Main exclusion criteria \\ a-1 Antitrypsin deficiency \\ Giant bullae \\ Previous thoracotomy or lung resection \\ Excessive sputum and/or bronchiectasis \\ Active infection \\ Unstable cardiological status \\ Active smoking
}

with the help of an automated in-house software analysis system (YACTA), which enhanced the emphysema distribution. This was confirmed by perfusion scintigraphy [16]. At baseline, the emphysema distribution was visualized and the total lung volume and emphysema index were estimated with YACTA analysis of the CT data [17]. In more detail, YACTA automatically detects the lung tissue $(<-500$ Hounsfield units, HU) based on threshold values and an anatomical knowledge-based algorithm and it excludes the tracheobronchial tree. For emphysema detection, a threshold of $-950 \mathrm{HU}$ is used, with a noise correction for voxels with a density of between -910 and -949 HU surrounded by at least 4 voxels with a density of $\leq-950 \mathrm{HU}[17,18]$. From the CT analysis, the volume of the segmented lung (lung volume), the volume of the segmented emphysema (emphysema volume), their ratio (pixel index, emphysema index), the volume of the excluded tracheobronchial tree and the 15 th percentile are calculated automatically. The 15th percentile is defined as the threshold HU value for which $15 \%$ of all lung voxels have a lower density value [19]. The 10th and 5th percentiles are also calculated. This procedure was followed by a second YACTA analysis of the $\mathrm{CT}$ at 90 days after the intervention, in order to assess possible lung volume reduction and changes in emphysema index and emphysema volume.

The LVRC (RePneuR, PneumRx Inc., Mountain View, USA) are made from preformed nitinol wire (fig. 1) that is delivered straight into the desired subsegmental bronchus via the working channel of a flexible bronchoscope; it recovers to a predetermined shape upon deployment. This supposedly results in the bending of the airway and the compression of the diseased lung parenchyma. In this manner, the coil tenses the surrounding tissue, increasing elastic recoil and redirecting air to healthier portions of the lung. LVRC exist in 3 different sizes (100, 125 and $150 \mathrm{~mm}$ ) to accommodate different-sized airways. Figure 2 demonstrates a patient's chest X-ray after the insertion of 10 coils into the right upper lobe.

Each procedure was performed under general anesthesia with a combination of rigid and flexible bronchoscopy as per hospital standards. It involved placing a total of 10 LVRC with fluoroscopic guidance (fig. 3 ) in 1 session into the subsegmental bronchi of the lobe most affected by emphysema. Further details of the coil 


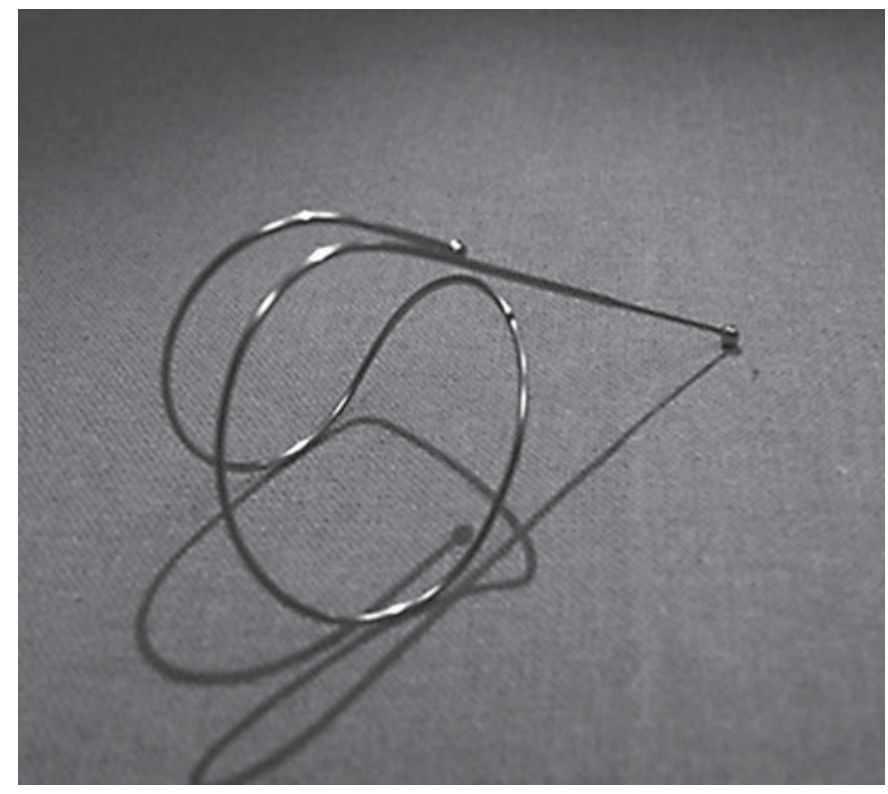

Fig. 1. RePneu ${ }^{\circledR}$ lung volume reduction coil.

design, function and insertion technique have been previously described in the literature [20].

According to our standard protocol, all patients received intravenous antibiotic prophylaxis (2nd-generation cephalosporin) during the procedure, followed by a second dose $8 \mathrm{~h}$ later and completed by an equivalent oral regime for a total of 7 days. Patients remained in hospital under observation for 4 days on average and received a chest radiograph immediately after the procedure and the next day.

Patients were assessed at baseline and after 30, 90 and 180 days, and probable complications were recorded. At each time point, PFT, 6MWT and questionnaires concerning dyspnea [the modified Medical Research Council (mMRC) dyspnea score] and QoL [the St. George's Respiratory Questionnaire (SGRQ)] were conducted and reported $[21,22]$. Radiological monitoring was performed with a chest radiograph at baseline and at 30,90 and 180 days and an MSCT scan at baseline and 90 days. Significant complications (severe hemorrhage, pneumothorax or death) were recorded.

\section{Statistical Analysis}

All continuous variables are presented as mean \pm SD. Normality of distribution was checked by employing Shapiro-Wilk's test. Twoway repeated measures analysis of variance (ANOVA) was used to assess differences at different time points. When the sphericity assumption did not hold, the multivariate results were used. For pairwise comparisons of adjacent time points, Bonferroni's adjusted $p$ values were reported. For ordinal values, Friedman's test was used to assess for multiple comparisons. Once the significance of potential risk factors had been assessed, multivariate linear regression analysis was performed using a stepwise method. To account for within-patient changes over time, linear fixed-effects models were fitted. Data were assessed for linear and quadratic trends over time. A quadratic trend is indicative of nonlinear variation such as a change of direction. $\mathrm{p}<0.05$ was considered statistically significant.

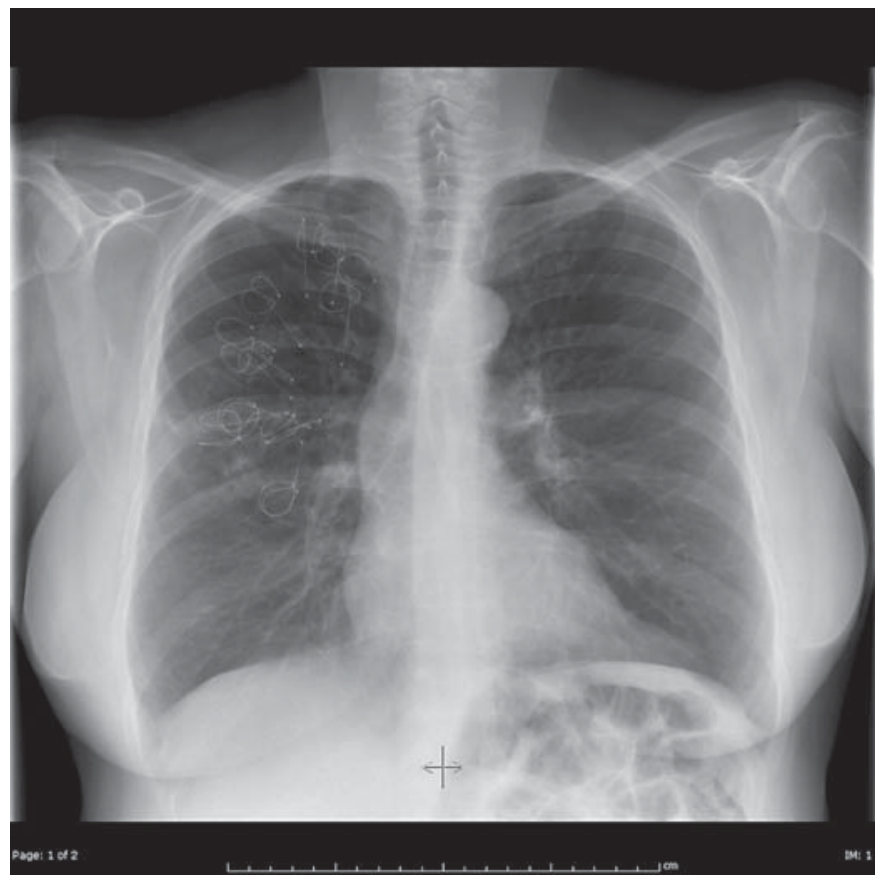

Fig. 2. Chest X-ray of a patient after insertion of 10 coils in the right upper lobe.

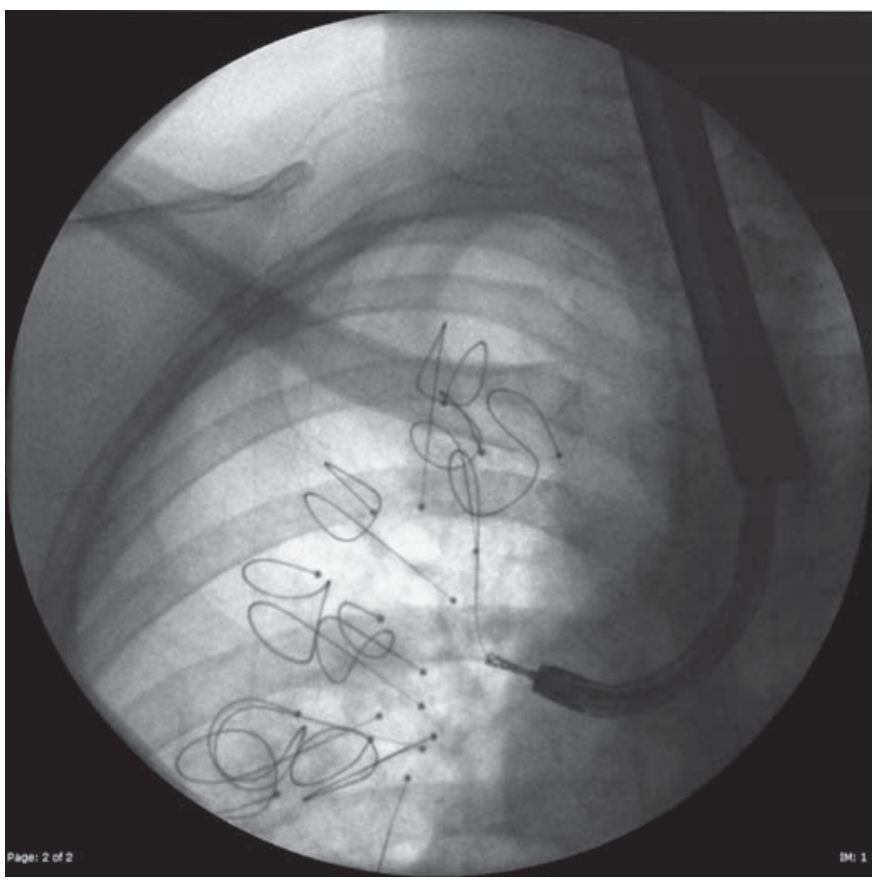

Fig. 3. Autofluorescence used for real-time visualization of coils' insertion. 
Table 2. Baseline characteristics of the 26 COPD patients included in the study

\begin{tabular}{lc}
\hline Demographics & \\
\hline Age, years & $66 \pm 8$ \\
Gender, male/female & $13 / 13$ \\
BMI, kg/m ${ }^{2}$ & $24 \pm 4$ \\
Blood gas analysis & \\
$\mathrm{PaO}_{2}$, mm Hg & $59 \pm 7$ \\
$\mathrm{PaCO}_{2}$, mm Hg & $44 \pm 7$ \\
pH & $7.42 \pm 0.03$ \\
Sat, \% & $92 \pm 3$ \\
Pulmonary lung function & \\
FEV, 1 & $0.67 \pm 0.17$ \\
FEV, \% predicted & $26 \pm 8$ \\
VC, 1 & $1.97 \pm 0.64$ \\
VC, \% predicted & $58 \pm 18$ \\
RV, l & $6.17 \pm 1.6$ \\
RV, \% predicted & $279 \pm 53$ \\
TLC, l & $8.16 \pm 1.72$ \\
TLC, \% predicted & $141 \pm 20$ \\
RV/TLC & $75 \pm 8$ \\
Exercise capacity & \\
6MWT, m & $216 \pm 107$ \\
QoL (SGRQ) score $(\mathrm{n}=25)$ & \\
Total & $65 \pm 12$ \\
Impact & $54 \pm 18$ \\
Activity & $86 \pm 12$ \\
Symptoms & $64 \pm 18$ \\
mMRC & $3 \pm 1$ \\
\hline
\end{tabular}

Values are given as the mean $\pm \mathrm{SD} . \mathrm{PaCO}_{2}=$ Partial arterial pressure of carbon dioxide; $\mathrm{PaO}_{2}=$ partial arterial pressure of oxygen; Sat $=$ saturation .

\section{Results}

During the study period (September 2011 to March 2013), 26 patients with heterogeneous emphysema were enrolled. No predefined cut-off value was used for determining the heterogeneity of emphysema, which we assessed with the YACTA analysis system and then confirmed by perfusion scintigraphy. Baseline characteristics of the patients are shown in table 2 .

All patients were treated unilaterally. The right upper lobe was treated in $15(58 \%)$ patients, the right lower lobe in $4(15 \%)$, the left upper lobe in $4(15 \%)$ and the left lower lobe in 3 (11\%). No periprocedural technical events occurred and none of the coils placed needed to be replaced or removed.

All patients completed the study and were reassessed at 30 days $(\mathrm{n}=26) ; 25$ were reassessed at 90 days (1 missed this follow-up and was reassessed at 180 days

LVRC in Heterogeneous Emphysema and Incomplete Fissures

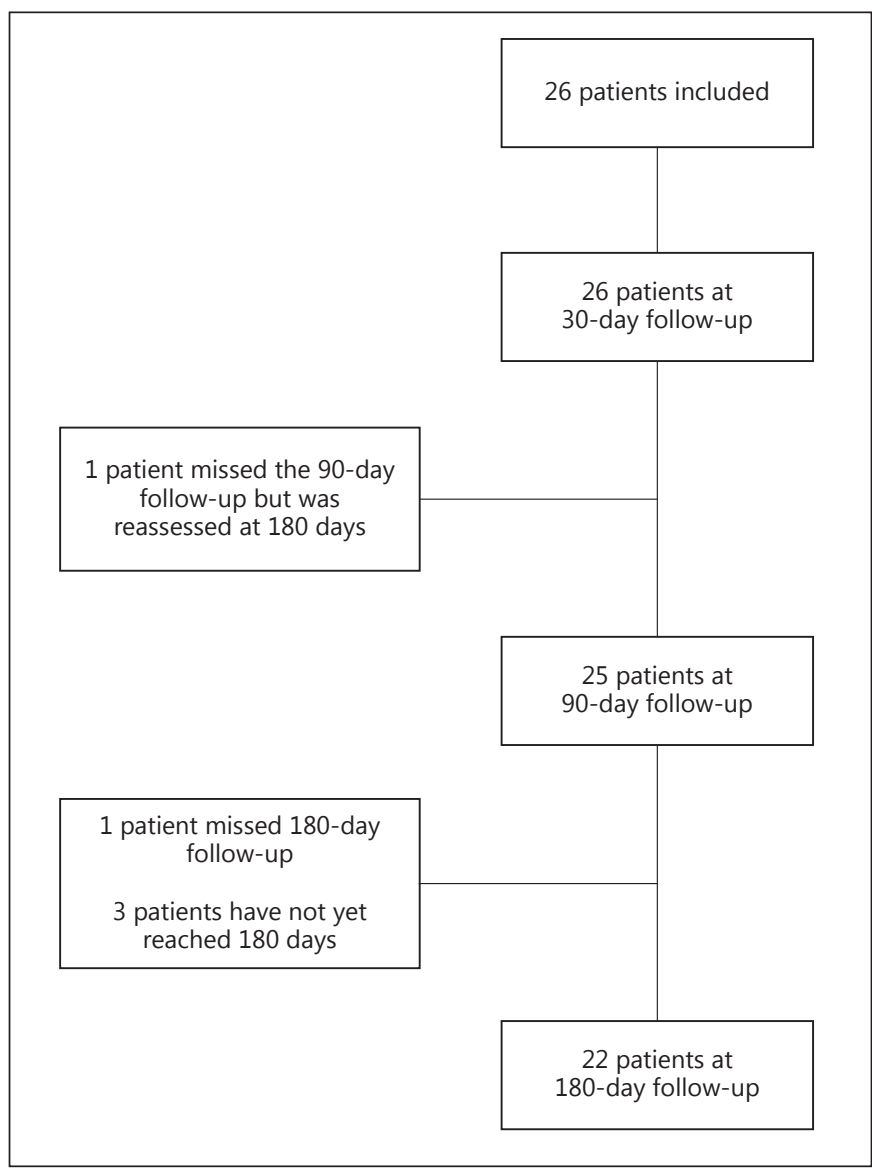

Fig. 4. Flowchart showing patient follow-up. One patient declined the PFT and 6MWT measurements but completed the dyspnea and SGRQ questionnaires and 2 patients could not perform the $6 \mathrm{MWT}$.

only) and 22 were reassessed at 180 days ( 1 missed the 180 -day follow-up and for 3 , the 180-day appointment is not yet due). At the 180-day follow-up, 1 patient declined the PFT and 6MWT measurements but completed the dyspnea (90-day mMRC) and SGRQ questionnaires (fig. 4).

MSCT scanning with YACTA analysis was performed at baseline and at the 90-day follow-up and showed a significant lung volume reduction $(7,039 \pm$ $1,463$ vs. $6,756 \pm 1,465 \mathrm{ml}, \mathrm{p}=0.02)$, a change in the emphysema index $(39 \pm 11$ vs. $36 \pm 11 \%, \mathrm{p}=0.04)$ and no change in the emphysema volume $(2,789 \pm 1,078$ vs. $2,797 \pm 1,027 \mathrm{ml})$.

\section{FEV $V_{1}$ Measurement}

$\mathrm{FEV}_{1}$ had improved significantly after 30 days and this improvement was sustained at 90 days after the intervention and tended to have decreased at the 180-day follow- 
Table 3. Lung function parameters, 6MWT and QoL in COPD patients at baseline and up to the 180-day follow-up

\begin{tabular}{|c|c|c|c|c|c|}
\hline \multicolumn{6}{|l|}{ Pulmonary lung function } \\
\hline $\mathrm{FEV}_{1}, 1$ & $0.67 \pm 0.17$ & $0.74 \pm 0.21^{*}$ & $0.78 \pm 0.25^{*}$ & $0.73 \pm 0.21(\mathrm{n}=21)$ & $<0.001$ \\
\hline $\mathrm{FEV}_{1}, \%$ predicted & $26 \pm 8$ & $29 \pm 8$ & $30 \pm 9^{*}$ & $29 \pm 8(n=21)$ & $<0.001$ \\
\hline $\mathrm{VC}, 1$ & $1.97 \pm 0.64$ & $2.15 \pm 0.70$ & $2.34 \pm 0.78^{*}$ & $2.29 \pm 8.7(\mathrm{n}=21)$ & 0.001 \\
\hline $\mathrm{RV}, \%$ predicted & $279 \pm 53$ & $251 \pm 38$ & $247 \pm 60^{*}$ & $265 \pm 47(\mathrm{n}=21)$ & 0.005 \\
\hline TLC, 1 & $8.16 \pm 1.72$ & $7.72 \pm 1.36$ & $7.93 \pm 1.65$ & $8.05 \pm 1.56(\mathrm{n}=21)$ & NS \\
\hline TLC, $\%$ predicted & $141 \pm 20$ & $133 \pm 13$ & $135 \pm 17$ & $145 \pm 19(\mathrm{n}=21)$ & NS \\
\hline $\mathrm{RV} / \mathrm{TLC}$ & $75 \pm 8$ & $71 \pm 7$ & $69 \pm 10^{*}$ & $72 \pm 9(\mathrm{n}=21)$ & 0.001 \\
\hline Exercise capacity (6MWT), m & $216 \pm 107$ & $247 \pm 105^{*}(\mathrm{n}=25)$ & $262 \pm 97^{*}(\mathrm{n}=23)$ & $262 \pm 112(\mathrm{n}=19)$ & 0.001 \\
\hline \multicolumn{6}{|l|}{ Questionnaire scores } \\
\hline Symptoms & $64 \pm 18$ & $53 \pm 24$ & $47 \pm 16^{*}$ & $52 \pm 25$ & 0.012 \\
\hline mMRC (dyspnea) & $3.0 \pm 1.1$ & $2.6 \pm 1.3$ & $2.6 \pm 1.2$ & $2.4 \pm 1.3(\mathrm{n}=22)$ & NS \\
\hline
\end{tabular}

Values are given as the mean \pm SD. Repeated-measures analysis was used to test for statistical differences with post hoc Bonferroni correction for pairwise comparisons. NS = Not significant.

$* \mathrm{p}<0.05$ pairwise difference vs. baseline values with post hoc Bonferroni correction.

up. Compared to baseline values at 90 and 180 days after LVRC treatment, there was a $\triangle \mathrm{FEV}_{1}$ of $0.10 \pm 0.13$ and $0.04 \pm 0.12$ liters, respectively. $\mathrm{FEV}_{1}$ had improved by $>12 \%$ (minimal clinically significant change) in 14 of 25 (66\%) patients at 90 days and in 9 of 21 (43\%) patients at 180 days (table 3 ).

Fitted models were consequently used to account for the trends in within-patient changes over time, confirming a quadratic relationship between outcome variables and time. Intercepts and coefficients are characteristics of the models. Intercepts indicate the value of each parameter at baseline and coefficients are an indication of the rate of change of the outcome variable as time passes on a monthly basis. Accordingly, the model for $\mathrm{FEV}_{1}$ predicts an increase in $\mathrm{FEV}_{1}$ up to 90 days after intervention followed by a leveling off and a subsequent decrease (table 4; fig. 5).

\section{Remaining PFT Values}

Vital capacity (VC) and RV improved significantly at 30 days after intervention and the improvement was sustained at 90 days. TLC did not change after the intervention; however, RV/TLC was significantly lower at 90 days. At the 180-day follow-up, the PFT measurements tended
Table 4. Longitudinal analysis for specific parameters in 26 COPD patients receiving LVRC placement

\begin{tabular}{llllll}
\hline \multicolumn{5}{c}{ Intercept } & \multicolumn{4}{l}{ Coefficients } \\
\cline { 3 - 6 } & & $\begin{array}{l}\text { time } \\
\text { (linear } \\
\text { term) }\end{array}$ & $\mathrm{p}$ & $\begin{array}{l}\text { time } \\
\text { (quadratic } \\
\text { term) }\end{array}$ & $\mathrm{p}$ \\
& & & & \\
\hline $\mathrm{FEV}_{1}$ & 0.677 & 0.067 & $<0.0001$ & -0.014 & $<0.0001$ \\
$\mathrm{VC}$ & 1.969 & 0.194 & 0.002 & -0.025 & 0.0043 \\
$\mathrm{RV}$ & 5.776 & -0.405 & 0.0026 & 0.069 & 0.0013 \\
$6 \mathrm{KWD}$ & 215 & 25.220 & 0.0002 & -3.465 & 0.0003 \\
\hline
\end{tabular}

Longitudinal analysis was performed so as to quantify the patients' course over time as described by each parameter. Intercepts indicate the value of the respective parameter at time $=0$. Coefficients indicate the rate of change of each parameter as time passes, with 1 month being the time unit. The $\mathrm{p}$ values indicate the validity of the model.

to decrease but did not reach baseline values. The fitted models showed similar trends for RV and VC, namely, an improvement up to 90 days after the intervention followed by a leveling off and a subsequent decrease (table 4; fig. 5). 


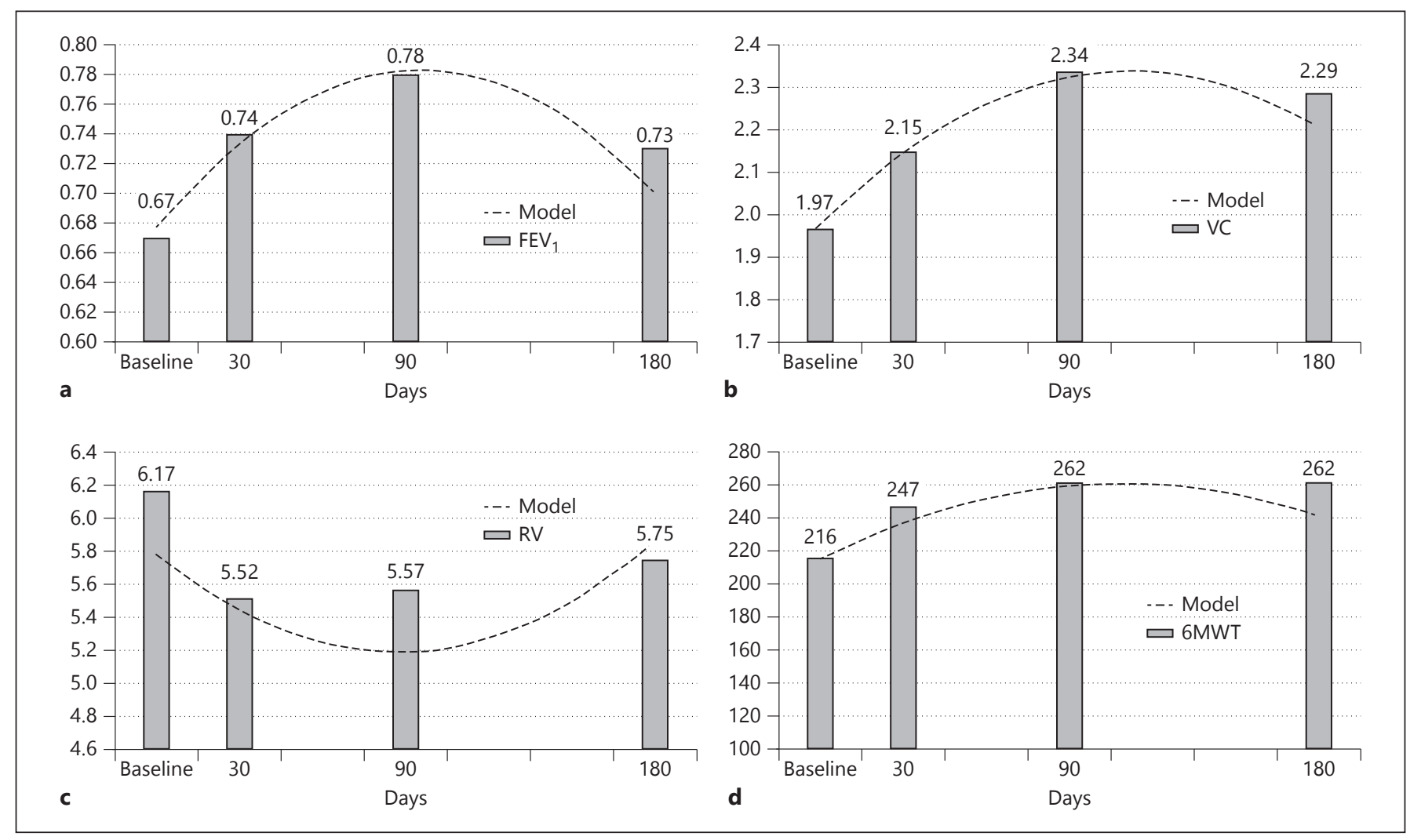

Fig. 5. $\mathrm{FEV}_{1}(\mathbf{a}), \mathrm{VC}(\mathbf{b}), \mathrm{RV}(\mathbf{c})$ and $6 \mathrm{MWT}(\mathbf{d})$ in 26 patients who underwent LVRC treatment at baseline and at 30,90 and 180 days after the intervention (bars represent mean values and lines represent predicted values according to the fitted quadratic model).

\section{Exercise Capacity}

6MWT improved significantly after 30 days; this improvement was sustained at the 90-day follow-up and tended to decrease at the 180-day follow-up (table 3). One patient did not complete the 6MWT at 30 days (for technical reasons) but did complete the 90 -day evaluation, 1 did not complete the 6MWT at 30 and 90 days and 1 declined the 90-day 6MWT evaluation. Of the patients that were reevaluated at 180 days $(n=22), 1$ declined the $6 \mathrm{MWT}$ measurement and 2 could not perform a $6 \mathrm{MWT}$ (fig. 4). Compared to baseline values, there was a $\triangle 6 \mathrm{MWT}$ of $47 \pm 54$ and $32 \pm 60 \mathrm{~m}$, respectively, at 90 and 180 days after LVRC treatment. Sixteen of 23 (69\%) patients improved by $>26 \mathrm{~m}$ (minimal clinically significant change) [23].

A fitted model was consequently used to account for trends in within-patient changes over time, also confirming a quadratic relationship between outcome variables and time. The model for $6 \mathrm{MWT}$ predicts an increase in $6 \mathrm{MWT}$ up to 90 days after the intervention followed by a leveling off and a subsequent decrease (table 4; fig. 5).

LVRC in Heterogeneous Emphysema and Incomplete Fissures

\section{QoL and Dyspnea Scores}

mMRC tended to be lower at the 30-, 90- and 180-day follow-ups; however, the value did not reach statistical significance. QoL assessed with the SGRQ was significantly improved after 30 and 90 days. The improvement was more pronounced within the domain of symptoms rather than the domains of activity and impact (table 3 ). SGRQ total score improved by $>4$ points (minimal clinically significant change) in 11 of $24(46 \%)$ patients at 90 days.

Univariate linear regression showed that the baseline $6 \mathrm{MWT}$ was negatively associated with a corresponding improvement at 90 days $(\beta-0.23,95 \% \mathrm{CI}-0.43$ to -0.037 , $\mathrm{p}=0.022)$ and baseline RV was positively associated with improvement in 6MWT at 90 days ( $\beta 14.33,95 \%$ CI 0.35 to $28.31, \mathrm{p}=0.04)$. Univariate analysis for all other clini$\mathrm{cal}$ (age, gender and $\mathrm{FEV}_{1}, \mathrm{VC}$ and TLC at baseline), procedural (lobe-treated, complications) or radiological, YACTA-analysis parameters (lung volume, emphysema volume, emphysema index, mean lung density and 15th, 10th and 5th percentiles) did not show statistically sig- 
nificant linear associations. Multivariate linear regression analysis was done with $\triangle 6 \mathrm{MWT}$ as the dependent variable and $6 \mathrm{MWT}$ and RV at baseline, i.e. the variables that were statistically significant at the univariate analysis, as the independent variables. In this analysis, worse performance in the 6MWT at baseline was independently associated with a greater improvement in 6MWT at the 90 day follow-up.

\section{Complication Rate}

The total complication rate was $54 \%(\mathrm{n}=14)$. Light hemorrhage occurred in 6 patients (23\%); this was selflimiting and did not require further endoscopic management. Significant complications included COPD exacerbation requiring antibiotic treatment without need for hospitalization in 6 patients (23\%), pneumothorax requiring insertion of a chest drain in 1 (4\%) and both COPD exacerbation and pneumothorax in 1 other patient (4\%). Therefore, the total rate of pneumothorax was $8 \%$.

\section{Discussion}

The main findings of this study are that LVRC placement resulted in an improved exercise capacity, QoL and lung function in a small cohort of patients with heterogeneous emphysema and incomplete fissures. The study also assessed the effect of LVRC in these patients. One of the main pathophysiological causes for dyspnea and exercise limitation in COPD patients with severe emphysema is static and dynamic hyperinflation of the lungs, which render the respiratory muscles inefficient $[24,25]$. Recently, ELVR techniques have gained interest as a means of decreasing hyperinflation and consequently offering the benefits of surgical lung volume reduction without the associated morbidity $[5,10,11]$. ELVR by means of endobronchial valve placement is probably the most widely used. However, benefits have been shown in patients with emphysema, in whom lobar atelectasis is achieved, namely, those patients without collateral ventilation [26]. LVRC overcomes this problem since it causes a lung volume reduction independent of collateral ventilation and can therefore be used in patients who are not candidates for ELVR that makes use of valves [27, 28]. In a previous study [20], we showed that this is safe and feasible in patients with severe COPD. The pathophysiological mechanism involved could be the improvement in lung mechanics due to the compression of destroyed lung parenchyma with the use of coils, resulting in volume reduction as well as an improvement in elastic recoil. This may result in less dynamic hyperinflation during exercise and thus improve exercise capacity.

Our study has shown that LVRC resulted in an initially significantly improved exercise capacity, as assessed by 6 MWT. A fitted model was used to better describe the trend of within-patient changes, which predicted an increase in 6MWT up to 3 months and then a subsequent leveling off and decrease at 6 months. The finding of improvement in 6MWT at 90 days is in accordance with previous studies $[27,28]$. Our study, however, showed that exercise capacity tended to decrease at 6 months. In a recent study [27], the improvement in $6 \mathrm{MWT}$ was sustained up to 6 months after the intervention, even though the values at 6 months tended to be lower than those at 3 months. This finding could be at least partially explained by the fact that the majority of these patients underwent a second procedure with treatment of a second lobe.

Another finding is the improvement in PFT values,

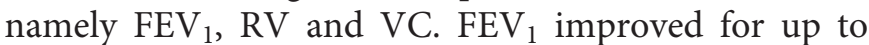
3 months after the procedure and tended to decrease at the 6-month follow-up although not to baseline values. An improvement in $\mathrm{FEV}_{1}, \mathrm{VC}$ and $\mathrm{RV}$ up to 3 months is in accordance with previously published data [27, 28]. In a recent study by Slebos et al. [27], $\triangle \mathrm{FEV}_{1}$ was significantly higher at 3 and 6 months compared to the baseline value. QoL improved by more than the minimal clinically significant difference of 4 points [29] and this improvement seemed to be sustained up to 6 months, as reported in other studies $[27,28]$.

Although exercise capacity had significantly improved at the 3-month follow-up, in approximately one third of the patients, this improvement did not reach the clinically significant value of $26 \mathrm{~m}$ [23]. This finding highlights the importance of identification of preprocedural characteristics which could correlate with good postprocedural outcome. Of the clinical, radiological and endoscopic characteristics assessed, a lower 6MWT and a higher RV at baseline correlated with the improvement in $6 \mathrm{MWT}$ at 90 days. In the multivariate analysis, only $6 \mathrm{MWT}$ at baseline was independently associated with the improvement of 6MWT at 90 days. It therefore seems that a lower initial performance in the 6MWT may predict an improvement in exercise capacity, as has been shown for patients undergoing lung volume reduction surgery [5]. However, due to the small number of patients, definite conclusions could not be drawn and this should be addressed in further studies.

The complication rate was similar to that reported by other studies [27, 28]. Mild hemorrhage that did not re-
58

Respiration 2014;88:52-60 DOI: $10.1159 / 000358441$
Kontogianni/Gerovasili/Gompelmann/ Schuhmann/Heussel/Herth/Eberhardt 
quire endoscopic or other management was recorded in 6 patients and COPD exacerbation without need for hospitalization was also recorded in 6 patients. Pneumothorax occurred in 2 patients, 1 of whom required chest drainage.

\section{Limitations}

This study has several limitations. Firstly, this is a retrospective analysis of a small, nonconsecutive patient cohort selected in a single center. A second limitation is the lack of a control group and also the fact that this was an unblinded study, which cannot exclude the possibility of a placebo effect being partially responsible for the observed improvements. It should be noted, however, that it is unlikely that improvement in exercise capacity and PFT could be solely attributed to a placebo effect. Finally, the results of the longitudinal analysis should be interpreted with caution due to the small sample size.

\section{Conclusion}

LVRC placement is a promising new technique in patients with advanced COPD and heterogeneous emphysema and it has an acceptable safety profile. In this small cohort of patients with heterogeneous emphysema and incomplete fissures, LVRC improved exercise capacity, QoL and lung function for up to 3 months. This improvement seems to have leveled off and decreased at the 6-month follow-up, however. Further studies are needed to assess the long-term effects of LVRC in these patients.

\section{Acknowledgments}

Part of this study was supported by grants from the Bundesministerium für Bildung und Forschung (82DZL00401, 82DZL00402, 82DZL00404). Thank you to Oliver Weinheimer for accessing and maintaining the YACTA software and to Melanie Segovic for her application of computer-assisted emphysema quantification.

\section{Notification of Prior Abstract Publication/ Presentation}

Our results have been partially published in poster form at the ERS Congress in Barcelona in September 2014.

\section{Financial Disclosure and Conflicts of Interest}

C.P. Heussel has enclosed a COI statement. None of the other authors has any disclosures.

\section{References}

1 Pfeifer M: Chronic critically ill patients from a pneumonological perspective. Med Klin Intensivmed Notfmed 2013;108:279284.

-2 Fishman A, Martinez F, Naunheim K, Piantadosi S, Wise R, Ries A, Weinmann G, Wood DE: A randomized trial comparing lung volume-reduction surgery with medical therapy for severe emphysema. N Engl J Med 2003; 348:2059-2073.

3 Sciurba FC, Rogers RM, Keenan RJ, Slivka WA, Gorcsan J 3rd, Ferson PF, Holbert JM, Brown ML, Landreneau RJ: Improvement in pulmonary function and elastic recoil after lung-reduction surgery for diffuse emphysema. N Engl J Med 1996;334:1095-1099.

-4 Criner GJ, Cordova FC, Furukawa S, Kuzma AM, Travaline JM, Leyenson V, O'Brien GM: Prospective randomized trial comparing bilateral lung volume reduction surgery to pulmonary rehabilitation in severe chronic obstructive pulmonary disease. Am J Respir Crit Care Med 1999;160:2018-2027.

$\checkmark 5$ Sciurba FC, Ernst A, Herth FJ, Strange C, Criner GJ, Marquette CH, Kovitz KL, Chiacchierini RP, Goldin J, McLennan G; VENT
Study Research Group: A randomized study of endobronchial valves for advanced emphysema. N Engl J Med 2010;363:12331244.

6 Wan IY, Toma TP, Geddes DM, Snell G, Williams T, Venuta F, Yim AP: Bronchoscopic lung volume reduction for end-stage emphysema: report on the first 98 patients. Chest 2006; 129:518-526.

7 Springmeyer SC, Bolliger CT, Waddell TK, Gonzalez X, Wood DE; IBV Valve Pilot Trials Research Team: Treatment of heterogeneous emphysema using the spiration IBV valves. Thorac Surg Clin 2009;19:247-253.

8 Sterman DH, Mehta AC, Wood DE, Mathur PN, McKenna RJ Jr, Ost DE, Truwit JD, Diaz P, Wahidi MM, Cerfolio R, Maxfield R, Musani AI, Gildea T, Sheski F, Machuzak M, Haas AR, Gonzalez HX, Springmeyer SC; IBV Valve US Pilot Trial Research Team: A multicenter pilot study of a bronchial valve for the treatment of severe emphysema. Respiration 2010;79:222-233.

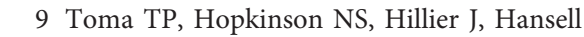
DM, Morgan C, Goldstraw PG, Polkey MI, Geddes DM: Bronchoscopic volume reduc- tion with valve implants in patients with severe emphysema. Lancet 2003;361:931-933.

10 Herth FJ, Gompelmann D, Ernst A, Eberhardt R: Endoscopic lung volume reduction. Respiration 2010;79:5-13.

11 Gasparini S, Zuccatosta L, Bonifazi M, Bolliger CT: Bronchoscopic treatment of emphysema: state of the art. Respiration 2012;84: 250-263.

12 Koenigkam-Santos M, Puderbach M, Gompelmann D, Eberhardt R, Herth F, Kauczor HU, Heussel CP: Incomplete fissures in severe emphysematous patients evaluated with MDCT: incidence and interobserver agreement among radiologists and pneumologists. Eur J Radiol 2012;81:4161-4166.

13 Gompelmann D, Heussel CP, Eberhardt R, Snell G, Hopkins P, Baker K, Witt C, Valipour A, Wagner M, Stanzel F, Egan J, Ernst A, Kesten S, Herth FJ: Efficacy of bronchoscopic thermal vapor ablation and lobar fissure completeness in patients with heterogeneous emphysema. Respiration 2012;83:400-406.

14 Gompelmann D, Eberhardt R, Herth FJ: Collateral ventilation. Respiration 2013;85:515520 
15 Koenigkam-Santos M, de Paula WD, Owsijewitsch M, Wielpütz MO, Gompelmann D, Schlemmer HP, Kauczor HU, Heussel CP, Puderbach M: Incomplete pulmonary fissures evaluated by volumetric thin-section CT: semi-quantitative evaluation for small fissure gaps identification, description of prevalence and severity of fissural defects. Eur J Radiol 2013;82:2365-2370.

16 Thurnheer R, Engel H, Weder W, Stammberger U, Laube I, Russi EW, Bloch KE: Role of lung perfusion scintigraphy in relation to chest computed tomography and pulmonary function in the evaluation of candidates for lung volume reduction surgery. Am J Respir Crit Care Med 1999;159:301-310.

17 Heussel CP, Achenbach T, Buschsieweke C, Kuhnigk J, Weinheimer O, Hammer G, Düber C, Kauczor HU: Quantification of pulmonary emphysema in multislice-CT using different software tools. Rofo 2006;178:987-998.

18 Achenbach T, Buschsieweke C, Gerhards A, Gast K, Heussel CP, Thelen M: Does HRCTemphysema index represent the entire lung? Fortschr Röntgenstr 2005;177:655-659.
19 Newell JD, Hogg JC, Snider GL: Report of a workshop: quantitative computed tomography scanning in longitudinal studies of emphysema. Eur Respir J 2004;23:769-775.

20 Herth FJ, Eberhardt R, Gompelmann D, Slebos DJ, Ernst A: Bronchoscopic lung volume reduction with a dedicated coil: a clinical pilot study. Ther Adv Respir Dis 2010;4:225231.

21 Mahler DA, Wells CK: Evaluation of clinical methods for rating dyspnea. Chest 1988;93: 580-586.

22 Jones PW, Quirk FH, Baveystock CM, Littlejohns P: A self-complete measure of health status for chronic airflow limitation. The St. George's Respiratory Questionnaire. Am Rev Respir Dis 1992;145:1321-1327.

23 Puhan MA, Chandra D, Mosenifar Z, Ries A, Make B, Hansel NN, Wise RA, Sciurba F: The minimal important difference of exercise tests in severe COPD. Eur Respir J 2011;37:784790.

24 Ofir D, Laveneziana P, Webb KA, Lam YM, O’Donnell DE: Mechanisms of dyspnea during cycle exercise in symptomatic patients with GOLD stage I chronic obstructive pulmonary disease. Am J Respir Crit Care Med 2008; 177:622-629.
25 O’Donnell DE, Revill SM, Webb KA: Dynamic hyperinflation and exercise intolerance in chronic obstructive pulmonary disease. Am J Respir Crit Care Med 2001;164:770-777.

26 Herth FJ, Noppen M, Valipour A, Leroy S, Vergnon JM, Ficker JH, Egan JJ, Gasparini S, Agusti C, Holmes-Higgin D, Ernst A: Efficacy predictors of lung volume reduction with Zephyr valves in a European cohort. Eur Respir J 2012;39:1334-1342.

27 Slebos DJ, Klooster K, Ernst A, Herth FJ, Kerstjens HA: Bronchoscopic lung volume reduction coil treatment of patients with severe heterogeneous emphysema. Chest 2012;142: 574-582.

28 Shah PL, Zoumot Z, Singh S, Bicknell SR, Ross ET, Quiring J, Hopkinson NS, Kempet SV: Endobronchial coils for the treatment of severe emphysema with hyperinflation (RESET): a randomised controlled trial. Lancet Respir Med 2013;1:233-240.

29 Jones PW: St. George’s Respiratory Questionnaire: MCID. COPD 2005;2:75-79. 